
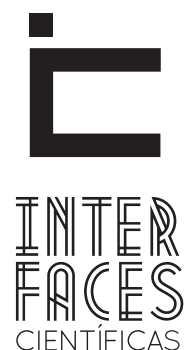

EDUCAÇÃO

ISSN IMPRESSO 2316-333X

ISSN ELETRÔNICO 2316-3828

DOI 10.17564/2316-3828.2016v4n3p151-158

\title{
ATHOS, PATHOS E LOGOS E O DISCURSO DOS CANDIDATOS A PRESIDENTE DO BRASIL NAS ELEIÇÕES DE 2014
}

Silvio Benitez ${ }^{1}$

\section{RESUMO}

O texto pretende fazer uma reflexão sobre o Ethos, Pathos e Logos segundo alguns autores bem como relacionar, a título de exemplo, com alguns discursos proferidos pelos candidatos a presidente da república do Brasil nas eleições de 2014, os candidatos são Aécio Neves, Dilma Roussef e Marina Silva. 0 método utilizado foi analisar os discursos retirados da revista Veja, comparando com os conceitos de autores sobre o assunto. 0 resultado obtido foi de que 0 discurso dos candidatos em tela deixa a desejar em termos de qualidade, reforçando a importância de estudarmos sobre o assunto, considerando que a boa retórica é fundamental para o sucesso profissional e pessoal de todos.

\section{PALAVRA-CHAVE}

Análise de Discurso. Ethos. Pathos. Logos. 


\section{ABSTRACT}

The text aims to reflect on the Ethos, Pathos and Logos according to some authors and relate, for example , with some speeches by candidates for president of the Republic of Brazil in the 2014 elections, candidates are Aécio Neves, Dilma Roussef and Marina Silva. The method used to analyze the speeches taken from Veja magazine and comparing the concepts of authors on the subject. The result was that the speech of candidates on screen leaves to be desired in terms of quality, reinforcing the importance of study on the subject considering that good rhetoric is key to professional and personal success of all.

\section{PALAVRA-CHAVE}

Analysis of Speech, Ethos, Pathos, Logos.

\section{RESUMEN}

El texto tiene como objetivo reflexionar sobre el Ethos, Pathos y Logos de acuerdo con algunos autores y se refieren, por ejemplo, con algunos discursos de los candidatos a la presidencia de la República de Brasil en las elecciones de 2014, los candidatos son Aécio Neves, Dilma Rousseff y Marina Silva. El método utilizado fue analizar los discursos tomados de la revista Veja y comparando con los conceptos de autores sobre el tema. El resultado fue que el discurso de los candidatos en la pantalla es débil en términos de calidad, lo que refuerza la importancia de estudiar sobre el tema teniendo en cuenta que buena retórica es esencial para el éxito profesional y personal de todos.

\section{PALABRAS CLAVE}

Análisis de expresión. Ethos. Pathos. Logos 


\section{INTRODUÇÃO}

A retórica faz parte de nosso dia a dia, saber conversar, saber convencer e, principalmente, saber argumentar é fundamental para nossa sobrevivência em tempos onde a comunicação se transforma em ritmo acelerado, Abreu (2008) nos da uma definição exata sobre argumentação:

Segundo o senso comum, argumentar é vencer alguém, forçá-lo a submeter-se à nossavontade. Definição errada! Von Clausewitz, o gênio militar alemão, utiliza-a para definirguerra e não argumentação. Seja em família, no trabalho, no esporte ou na política, saberargumentar é, emprimeiro lugar, saber integrar-se ao universo do outro. E também obteraquilo que queremos, mas de modo cooperativo e construtivo, raduzindo nossa verdadedentro da verdade do outro. (ABREU, 2008, p. 3).

A importância desse processo de comunicação vem de longa data, se voltarmos na história vamos perceber que a retórica está intimamente ligado a democracia devido ao poder e à necessidade de argumentar a fala, o discurso enfim, a ideia que se propõe disseminar, essa arte é estudada desde os primórdios da democracia:

A retórica, ou arte de convencer e persuadir, surgiu em Atenas, na Grécia antiga, por volta de 427 a.C, quando os atenienses, tendo consolidado na prática os princípios do legislador Sólon, estavam vivendo a primeira experiência de democracia de que se tem notícia na História. Ora, dentro desse novo estado de coisas, sem a presença de autoritarismo de qualquer espécie, era muito importante que os cidadãos conseguissem dominar a arte de bem falar e de argumentar com as pessoas, nas assembléias populares e nos tribunais. Para satisfazer essa necessidade, afluíram a Atenas, vindo sobretudo das colônias gregas da época, mestres itinerantes que tinham competência para ensinar essa arte. Eles se autodenominavam sofistas, sábios, aqueles que professam a sabedoria. Os mais importantes foram Protágoras e Górgias. (ABREU, 2002, p. 10).

Não restam dúvidas que argumentar, convencer, persuadir, em nosso dia a dia tornou-se fundamental para a sobrevivência das pessoas não só no campo profissional, mas também pessoal, sempre estamos sendo desafiados a argumentar como forma de convencer alguém. Abreu (2008) nos explica qual a diferença entre Argumentar, convencer e persuadir:

\begin{abstract}
Argumentar é a arte de convencer e persuadir. Convencer é saber gerenciar informação, é falar à razão do outro, demonstrando, provando. Etimologicamente significa vencer junto com o outro (com + vencer) e não contra o outro. Persuadir é saber gerenciar relação, é falar à emoção do outro. A origem dessa palavra está ligada à preposição per, "por meio de" e Suada, deusa romana da persuasão. Significa "fazer algo por meio de auxilio divino". Mas em que convencer se diferencia de persuadir? Convencer é construir algo no campo das ideias. Quando convencemos alguém, esse alguém passa a pensar como nós. Persuadir é construir no terreno das emoções, é sensibilizar o outro para agir. Quando persuadimos alguém, esse alguém realiza algo que desejamos que realize. (ABREU, 2002, p. 9).
\end{abstract}

\section{ETHOS, PATHOS E LOGOS}

Várias foram as técnicas para estudar a retórica, porém, na obra A Retórica de Aristóteles, o filosofo grego aborda a eficácia de um discurso por meio de três conceitos: ethos, logos e pathos, melhor descritos como as três provas engendradas pelo discurso. Essa tríade, segundo Aristóteles, é garantidora da persuasão do ato discursivo:

\footnotetext{
Aristóteles considera que o discurso engendra três provas - ethos, logos e pathos - que são, na realidade, qualidades que o orador deve demonstrar ao proferir um discurso. Essas provas seriam, basicamente, de três espécies: as que residem no caráter moral do orador, outras, baseadas na disposição do ouvinte e, por último, mas não menos importante, as que se baseiam no próprio discurso. Dessa forma, para Aristóteles, a persuasão está garantida quando: persuade-se pelo caráter (ethos), persuade- se pela disposição dos ouvintes quando estes sentem emoção (pathos) e, enfim, persuadimos pelo discurso em si (logos). (ARISTOTELES, 1998, [s.p.]).
} 
ETHOS - O Ethos é voltado para o orador ele é o que permite o orador parecer "digno de fé", mostra-se fidedigno, ao fazer prova de ponderação de simplicidade sincera de amabilidade. Percebam que o autor utiliza a palavra "parecer" no lugar de "ser" porque para Aristóteles "o orador deve mostras [seus traços de personalidade ao auditório (pouco importando sua sinceridade) para causar boa impressão" (CHARAUDEU, 2008, p. 114).

Dentre outras estratégias do discurso político destacamos o Ethos da humanidade como forma de convencer o público:

O Ethos de humanidade constitui igualmente um imaginário importante para a imagem do político. O "ser humano" é mensurado pela capacidade de demonstrar sentimentos, compaixão para com aqueles que sofrem, mas o é também pela capacidade de confessar suas fraquezas, de mostrar quais são seus gostos, até os mais íntimos. "Para ser um homem público, não é preciso ser menos homem”. (CHARAUDEU, 2008 p. 148).

Assim como o ethos da humanidade contribui para convencer o público também o ethos da solidariedade se apresenta como peça fundamental nesse jogo da argumentação:

O Ethos da solidariedade faz do político um ser que não somente está atento às necessidades dos outros, mas que as partilha e se torna responsável por elas. A solidariedade caracteriza-se pela vontade de estar junto, de não se distinguir dos outros membros do grupo e, sobretudo, de unir-se a eles a partir do momento em que se encontrarem ameaçados. Aquele que é solidário não está em uma posição diferente da dos outros; ele partilha as mesmas ideias. (CHARAUDEU, 2008 p. 119).

Outro fator preponderante na estratégia o discurso político é o Ethos de credibilidade que:

De maneira geral, um indivíduo pode ser julgado digo de crédito se houver condições de verificar que aquilo que ele diz corresponde sempre ao que ele pensa (condição de sinceridade ou de transparência) que ele tem os meios de por em pratica o que anuncia ou promete (condição de performance), e que o que ele anuncia e aplica é seguido de efeito (condições de eficácia) No caso oposto, revelar-se mentiroso, incapaz de honrar suas promessas u de realizar os objetivos perseguidos, só pode desacreditar o sujeito. (CHARAUDEU, 2008 p. 119).

Assim como o ethos da credibilidade o ethos da virtude se apresenta de igual importância porque,

[...] supõe que ele, como representante do povo, é quem dá o exemplo. Esse ethos exige que o político demonstre sinceridade e fidelidade, a que se deve acrescentar uma imagem de honestidade pessoal. Esse gênero de imagens se constrói através do tempo. Por exemplo, para julgar a fidelidade do político, particularmente a relacionada a seus compromisso, é preciso constatar que ele sempre seguiu a mesma linha de pensamento e de ação. (CHARAUDEU, 2008, p.122-123).

E como forma de comprovar que o político tem as habilidades necessárias para realizar determinada obra o ethos da competência diz que,

0 ethos da competência exige de seu possuidor, ao mesmo tempo, saber e habilidade: ele deve ter conhecimento profudo do domínio particular no qual exerce sua atividade, mas deve igualmente provar que tem os meios, o poder e a experiência necessáriapar arealizar completamente seus objetivos, obetendo resultados positivos. (CHARAUDEU, 2008, p. 125).

Um exemplo que tem no ETHOS sua principal característica é da candidata e atual presidente da república Dilma Rousseff que busca construir sua própria imagem por meio do discurso:

Tem uma coisa em economia que se chama índices antecedentes e os índices que evidenciam como é que é a situação atual. 0 que que são os índices antecedentes, por exemplo? A quantidade de papelão que é comprada, a quantidade de energia elétrica consumida, a quantidade de carros que são vendidos. Todos esses índices indicam uma recuperação no segundo semestre, vis-à-vis ao primeiro. (GAMA, 2014, p. 68).

O repórter da Veja Reinaldo Gama ainda reforça a característica da presidente Dilma Rousseff como sendo um "culto a sapiência e ao didatismo, que, muitas vezes, resulta no chamado 'dilmismo' - falta de clareza e de concordâncias, raciocínio tortuosos, que não se concluem" (GAMA, 2014, p. 68). 
PATHOS - Assim como o Ethos está voltado para o orador, o Pathos está voltado para o ouvinte e as emoções que estes sentem ao ouvirem discurso político, Willian Menezes (2007, p. 310) apresenta uma reflexão sobre as emoções no discurso político ou uma noção "produtiva da petemização do discurso político eleitoral". Para o autor "o estudo das emoções no discurso relaciona-se às estratégias de influencia e de manipulação, merecendo um destaque específico no interior das formulações sobre a argumentação" (MENEZES, 2007, p. 311).

Para Menezes (2007) duas tradições orientam os posicionamentos desse campo a primeira decorre da ação do logos ou racionalidade e é a lógico-normativa que;

[...] contempla um conjunto de teorias que enfatizam a possibilidade de uma "boa argumentação", centrado no bom fundamento ou validade dos argumentos, com contraposição a uma argumentação falaciosa, eivada por problemas que podem provocar danos à interação, portanto não válida. (MENEZES, 2007, p. 311).

A segunda ligada ao pathos é a abordagem retórica-discursiva que é vista como não válida, pois,

\begin{abstract}
[...] não segue as regras que asseguram o bom funcionamento. Uma argumentação não-válida, portanto, é considerada como um procedimento portador de vícios ou equívocos de raciocínio, com a presença de elementos subjetivos e irracionais. As emoções, as paixões e os sentimentos, enfim tudo aquilo que é da ordem do pathos seria responsável pela introdução desses desvios ou níveis de problemas, fragilizando a argumentação. (MENEZES, 2007, p. 311).
\end{abstract}

Portanto, segundo esse autor a logos sobre o pathos no bom discurso porque o o pathos poderia provocar a algum vícios ou equívocos quem podem ser:

Argumentum ad passioner: Essa tipologia apresenta a estrutura geral dos argumentos movidos pelo pathos. 0 sujeito argumentante (A) faz de sua teste ( $T$ ) um apelo às paixões $(P)$ do povo, em geral, ou de seu interpretante, em particular (B). (MENEZES, 2007, p. 311).
Um exemplo de Argumentum ad passioneré o pronunciamento da então candidata a presidente do Brasil Marina Silva, na campanha eleitoral de 2014 que, visando estancar a queda nas pesquisas, apelou para um discurso emotivo para explicar ao povo brasileiro sobre a continuidade dos programas sociais, principalmente o bolsa-família:

\begin{abstract}
Tudo o que minha mãe tinha pra oito filhos era um ovo e um pouco de farinha e sal. Eu me lembro de ter olhado para meu pai e minha mãe e perguntado: Vocês não vão comer? E minha mãe respondeu: "Nós não estamos com fome". Quem viveu essa experiência jamais acabará com o bolsa família. (BARROS; ZALIS, 2014, p. 50).
\end{abstract}

Seguindo a mesma linha Argumentum ad passioner a candidata do PT e atual presidenta Dilma Rousseff, apela ao emocional do eleitor na intenção de sensibilizar os brasileiros sobre uma consequência desastrosa de uma eventual independência do Banco Central defendida pela candidata Marina Silva:

\begin{abstract}
[...] Marina defendeu a necessidade de dar independência operacional ao BC, como maneira de incorporar definitivamente o combate à inflação como um avanço institucional, sem deixar essa ação a mercê das vontades do governo. Não falou nada de mais. É assim nos países desenvolvidos, nos quais, aliás, a inflação e os juros são muito menores que no Brasil. O PT, entretanto, viu aí uma oportunidade para explorar, de maneira torta, a emoção dos eleitores. Em uma peça para a TV, o texto diz que a mudança defendida por Marina daria aos banqueiros (sim aos banqueiros) a autonomia para decidir sobre juros, empregos e até salários, e, como sugerem as imagens, isso significaria menos comida na mesa das famílias. (SAKATE, 2014. p. 55).
\end{abstract}

LOGUS - Está voltado à razão, à argumentação, e, ao contrário do que se pensa, saber argumentar não é não é vencer por meio da força. Para Abreu (2002, p. 2) "saber argumentar é, em primeiro lugar, saber integrar-se ao universo do outro. É também obter aquilo que queremos, mas de modo cooperativo e construtivo, traduzindo nossa verdade dentro da verdade do outro".

O autor Antonio Suares de Abreu (2002, p. 4) em sua obra A Arte de Argumentar Gerenciando Razão e 
Emoção defende que "quando entramos em contato com o outro, não gerenciamos apenas informações, mas também a nossa relação com ele". 0 autor nos explica sobre a diferença entre argumentar, convencer e persuadir:

\begin{abstract}
Argumentar é a arte de convencer e persuadir. Convencer é saber gerenciar informação, é falar á razão do outro, demonstrando, provando. Etimológicamente, significa vencer junto com o outro (com + vencer) e não contra o outro. Persuadir é saber gerencia relação, é falar à emoção do outro. A origem dessa palavra está ligada a preposição per, "por meio de", e a Suada, deusa romana da persuasão. Significa "fazer algo por meio do auxilio divino". Mas em que convencerse diferencia de persuadir? Convencer é construir algo no campo das idéias. Quando convencemos alguém, esse alguém passa a pensar como nós. Persuadir é construir no terreno das emoções, e sensibilizar o outro para agir. Quando persuadimos alguém, esse alguém realiza algo que desejamos que ele realize. (ABREU, 2002, p. 7).
\end{abstract}

Como forma de fundamentar a arte de argumentar o autor estabelece as "Técnicas Argumentativas - que são os fundamentos que estabelecem a ligação entre as teses de adesão inicial e a tese principal" (ABREU, 2002, p. 14) e, ainda, os Argumentos Fundamentados na Estrutural do Real fundado a uma descria objetiva dos fatos, como o "Argumento pragmático que fundamenta-se na relação de dois acontecimento sucessivos por meio de um vinculo casual" (ABREU, 2002, p. 15) e a "Argumentação pelo Exemplo que acontece quando sugerimos a imitação das ações de outras pessoas" (ABREU, 2002, p.16).

Como exemplo de logos, que tem na razão sua principal característica, temos o discurso do candidato a presidência do Brasil nas eleições de 2014, senador Aécio Neves que em seu discurso procura reforçar a racionalidade de suas ações:

Nós vamos ter uma política de fronteira e de controle de entrada de drogas diferente dessa que esta aí [...]. Nós só estabeleceremos negociação, parcerias e apoios a esses países quando eles começarem a atuar internamente, dentro das suas fronteiras para coibir a produção da de drogas. (GAMA, 2014. p. 69).
O repórter da Revista Veja, Reinaldo Gama ainda reforça a característica do candidato "esforço em passar a ideia de uma postura propositiva, clara e racional, evidenciando que só se chegará a um ponto se cumpridas determinadas condições” (GAMA, 2014, p. 69).

\section{CONCLUSÃO}

0 texto nos leva a reflexão sobre a importância das técnicas de análise de discurso, principalmente o Ethos, Pathos e Logos para a elaboração e análise de um discurso a altura dos candidatos à presidência da republica, como o próprio repórter da revista veja Reinaldo Gama (2014, p. 69) afirma "longe de exibir uma oratória extraordinária, que marcou a trajetória de Carlos Lacerda, por exemplo, não apenas Dilma, Marina e Aécio têm no discurso uma limitação que as campanhas se bateram para superar", ou seja, o discurso dos candidatos deixam muito a desejar em termos de qualidade de retórica. Por isso a necessidade de acadêmico e demais pessoas que desejam ter boa oratória a importância de conhecer sobre as técnicas de análise de discurso.

\section{REFERÊNCIAS}

ABREU, A. S. de. A arte de argumentar: gerenciando razão e emoção. 5.ed. São Paulo. Ateliê, 2002. p.45-66.

ARISTÓTELES. Retórica. Tradução Manuel Alexandre Júnior, Paulo Farmhouse Alberto e Abel do Nascimento Pena. Lisboa: Imprensa Nacional - Casa da Moeda, 1998.

BARROS, Mariana; ZALIS, Pieter. A emoção vai ao palanque. Revista Veja. 2392.ed. ano 47, n.39, São Paulo: Abril, 24 set. 2014.

CHARAUDEU, Patrick. Discurso político. Tradução Fabiana Komesu e Dílson Ferreira da Cruz. São Paulo: Contexto, 2008. 
GAMA. Reinaldo. Retrato falado para os eleitores. Revista Veja. 2394.ed., ano 47, n.41, , São Paulo: Abril, 8 out. 2014.

MACHADO, Ida Lucia; MENEZES, William; MENDES. Emilia (Org.). As emoções no discurso. V.1, Rio de Janeiro: Lucerna, 2007.
REBOUL, O. Introdução à retórica. Tradução Ivone CastilhoBenedetti. 2.ed. São Paulo: Martins Fontes, 2000.

SAKATE. Marcelo. O BC atropelado pelo terrorismo. Revista Veja. 2392.ed., ano 47, n.39. São Paulo: Abril, 24 set. 2014. 
